\title{
Global phenological insensitivity to shifting ocean temperatures among seabirds
}

Katharine Keogan ${ }^{1 *}$, Francis Daunt ${ }^{2}$, Sarah Wanless ${ }^{2}$, Richard A. Phillips ${ }^{3}$, Craig A. Walling ${ }^{1}$, Philippa Agnew ${ }^{4}$, David G. Ainley ${ }^{5}$, Tycho Anker-Nilssen ${ }^{6}$, Grant Ballard ${ }^{7}$, Robert T. Barrett ${ }^{8}$, Kerry J. Barton ${ }^{9}$, Claus Bech ${ }^{10}$, Peter Becker ${ }^{11}$, Per-Arvid Berglund ${ }^{12}$, Loïc Bollache ${ }^{13,14}$, Alexander L. Bond $^{15,16}$, Sandra Bouwhuis ${ }^{11}$, Russell W. Bradley ${ }^{7}$, Zofia M. Burr ${ }^{17}$, Kees Camphuysen ${ }^{18}$, Paulo Catry $^{19}$, Andre Chiaradia ${ }^{20,21}$, Signe Christensen-Dalsgaard ${ }^{6}$, Richard Cuthbert ${ }^{15}$, Nina Dehnhard ${ }^{22}$, Sébastien Descamps ${ }^{23}$, Tony Diamond ${ }^{24}$, George Divoky ${ }^{25}$, Hugh Drummond ${ }^{26}$, Katie M. Dugger ${ }^{27}$, Michael J. Dunn ${ }^{3}$, Louise Emmerson ${ }^{28}$, Kjell Einar Erikstad ${ }^{23,29}$, Jérôme Fort ${ }^{30}$, William Fraser ${ }^{31}$, Meritxell Genovart ${ }^{32}$, Olivier Gilg ${ }^{13,33}$, Jacob González-Solís ${ }^{34}$, José Pedro Granadeiro ${ }^{35}$, David Gremillet $^{36,37}$, Jannik Hansen ${ }^{38}$, Sveinn A. Hanssen ${ }^{6}$, Mike Harris ${ }^{2}$, April Hedd ${ }^{39}$, Jefferson Hinke ${ }^{40}$, José Manuel Igual $^{32}$, Jaime Jahncke ${ }^{7}$, Ian Jones ${ }^{41}$, Peter J. Kappes ${ }^{42}$, Johannes Lang ${ }^{13,43}$, Magdalene Langset $^{6}$, Amélie Lescroël ${ }^{36}$, Svein-Håkon Lorentsen ${ }^{6}$, Phil O'B. Lyver ${ }^{44}$, Mark Mallory ${ }^{45}$, Børge Moe $^{6}$, William A. Montevecchi ${ }^{46}$, David Monticellii ${ }^{47}$, Carolyn Mostello ${ }^{48}$, Mark Newell ${ }^{2}$, Lisa Nicholson ${ }^{49}$, Ian $\mathrm{Nisbet}^{50}$, Olof Olsson ${ }^{51}$, Daniel Oro ${ }^{32}$, Vivian Pattison ${ }^{52}$, Maud Poisbleau ${ }^{22}$, Tanya Pyk $^{53}$, Flavio Quintana ${ }^{54}$, Jaime A. Ramos ${ }^{47}$, Raül Ramos ${ }^{34}$, Tone Kirstin Reiertsen ${ }^{23}$, Cristina Rodríguez $^{26}$, Peter Ryan ${ }^{55}$, Ana Sanz-Aguilar ${ }^{32}$, Niels M. Schmidt ${ }^{56}$, Paula Shannon ${ }^{57}$, Benoit Sittler ${ }^{13,58}$, Colin Southwell ${ }^{28}$, Christopher Surman ${ }^{49}$, Walter S. Svagelj ${ }^{59}$, Wayne Trivelpiece ${ }^{60}$, Pete Warzybok $^{7}$, Yutaka Watanuki ${ }^{61}$, Henri Weimerskirch ${ }^{62}$, Peter R. Wilson ${ }^{63}$, Andrew G. Wood ${ }^{3}$, Albert B. Phillimore ${ }^{1} \uparrow$, Sue Lewis ${ }^{1,2} \uparrow$

*Corresponding author

$\dagger$ These authors contributed equally to this work.

${ }^{1}$ Institute of Evolutionary Biology, University of Edinburgh, Ashworth Laboratories, Charlotte Auerbach Road, EH9 3FL, United Kingdom

${ }^{2}$ Centre for Ecology \& Hydrology, Bush Estate, Penicuik, Midlothian EH26 0QB, United Kingdom

${ }^{3}$ British Antarctic Survey, Natural Environment Research Council, High Cross, Madingley Road, Cambridge, Cambridgeshire CB3 0ET, United Kingdom

${ }^{4}$ Oamaru Blue Penguin Colony, Waterfront Road, Oamaru 9400, New Zealand

${ }^{5}$ HT Harvey and Associates, 983 University Avenue, Building D, Los Gatos, CA 95032 USA

${ }^{6}$ Norwegian Institute for Nature Research (NINA), P.O. Box 5685 Torgard, 7034 Trondheim, Norway

${ }^{7}$ Point Blue Conservation Science, 3820 Cypress Drive, Suite 11, Petaluma, CA 94954, USA

${ }^{8}$ Department of Natural Sciences, Tromsø University Museum, PO Box 6050 Langnes, NO-9037

Tromsø, Norway

${ }^{9}$ Landcare Research, Private Bag 6, Nelson, New Zealand

${ }^{10}$ Department of Biology, Norwegian University of Science and Technology, Norway

${ }^{11}$ Institute of Avian Research, An der Vogelwarte 21, 26386 Wilhelmshaven, Germany

${ }^{12}$ Institute of Marine Research, Department of Aquatic Resources, Swedish University of Agricultural Sciences, Sweden

${ }^{13}$ Groupe de Recherche en Ecologie Arctique, 16 rue de Vernot, F-21440 Francheville, France

${ }^{14}$ Laboratoire Chrono-environnement, Université de Bourgogne France Comté, F-25000 Besançon, France

${ }^{15}$ RSPB Centre for Conservation Science, Royal Society for the Protection of Birds, The Lodge, Sandy, Bedfordshire, SG19 2DL, United Kingdom

${ }^{16}$ Department of Biology, Memorial University of Newfoundland, St. John's, Newfoundland and Labrador, A1B 3X9 Canada

${ }^{17}$ The University Centre in Svalbard, NO-9171 Longyearbyen, Norway 
${ }^{18}$ Department of Coastal Systems, Royal Netherlands Institute for Sea Research P.O. Box 59, 1790 AB Den Burg, Texel \& Utrecht University, Utrecht, Netherlands

${ }^{19}$ MARE - Marine and Environmental Sciences Centre, ISPA - Instituto Universitário, Rua Jardim do Tabaco 34, 1149-041 Lisbon, Portugal

${ }^{20}$ Phillip Island Nature Parks, PO Box 97 Cowes, Victoria 3922, Australia

${ }^{21}$ School of Biological Sciences, Monash University, Australia

${ }^{22}$ Department of Biology, Behavioural Ecology and Ecophysiology Group, University of Antwerp, Campus Drie Eiken, Universiteitsplein 1, 2610 Antwerp (Wilrijk), Belgium

${ }^{23}$ Norwegian Polar Institute (FRAM), High North Research Centre for Climate and the Environment, Tromsø, Norway

${ }^{24}$ University of New Brunswick, Fredericton N.B. E3B 5A3, Canada

${ }^{25}$ Friends of Cooper Island, 652 32nd Avenue E, Seattle, WA 98112, USA

${ }^{26}$ Instituto de Ecología, Universidad Nacional Autónoma de México, A.P. 70-275, 04510 DF, Mexico

${ }^{27}$ U.S. Geological Survey, Oregon Cooperative Fish and Wildlife Research Unit. Department of Fisheries and Wildlife, 104 Nash Hall, Corvallis, OR, USA

${ }^{28}$ Australian Antarctic Division, Channel Highway, Kingston, 7050, Tasmania, Australia

${ }^{29}$ Centre for Conservation Biology, Department of Biology, Norwegian University of Science and Technology, Trondheim, Norway.

${ }^{30}$ Littoral Environnement et Sociétés (LIENSs), UMR 7266 CNRS-Université de La Rochelle, La Rochelle, France

${ }^{31}$ Polar Oceans Research Group, Sheridan, MT 59749 USA

${ }^{32}$ Population Ecology Group, IMEDEA (CSIC-UIB), Esporles, Spain

${ }^{33}$ Laboratoire Biogéosciences, UMR CNRS 6282, Université de Bourgogne Franche Comté, Dijon, France

${ }^{34}$ Departament de Biologia Animal, Universitat de Barcelona, Av Diagonal 643, Barcelona 08028, Spain

${ }^{35}$ CESAM, Departamento de Biologia Animal, Faculdade de Ciências, Universidade de Lisboa, Campo Grande, 1749-016 Lisbon, Portugal

${ }^{36}$ Centre d'Ecologie Fonctionnelle et Evolutive, UMR 5175, CNRS - Université de Montpellier Université Paul-Valéry Montpellier - EPHE, Montpellier, France

${ }^{37}$ FitzPatrick Institute, DST-NRF Centre of Excellence at the University of Cape Town, Rondebosch 7701 , South Africa

${ }^{38}$ Department of Bioscience, Aarhus University, Denmark

${ }^{39}$ Wildlife Research Division, Science and Technology Branch, Environment Canada

${ }^{40}$ Antarctic Ecosystem Research Division, National Marine Fisheries Service, National Oceanic and Atmospheric Administration, La Jolla, USA

${ }^{41}$ Department of Biology, Memorial University. St. John's, Newfoundland and Labrador, A1B 3X9, Canada

${ }^{42}$ Oregon Cooperative Fish and Wildlife Research Unit, Department of Fisheries and Wildlife, 104

Nash Hall, Corvallis, OR, USA

${ }^{43}$ Clinic for Birds, Reptiles, Amphibians and Fish, Justus-Liebig-University Giessen, Frankfurte Str. 91-93, D-35392 Giessen, Germany

${ }^{44}$ Landcare Research, PO Box 6940, Lincoln, 7640, New Zealand

${ }^{45}$ Biology, Acadia University, Wolfville, Nova Scotia, Canada, B4P2R6

${ }^{46}$ Department of Psychology, Biology and Ocean Sciences, Memorial University of Newfoundland

${ }^{47}$ MARE - Marine and Environmental Sciences Centre, Department of Life Sciences, University of Coimbra, 3004-517 Coimbra, Portugal 
${ }^{48}$ Massachusetts Division of Fisheries and Wildlife, 1 Rabbit Hill Road, Westborough, MA 01581, USA

${ }^{49}$ Halfmoon Biosciences, 45 Heather Road, Ocean Beach, WA 6333, Australia

${ }^{50}$ I. C. T. Nisbet \& Company, 150 Alder Lane, North Falmouth, MA 02556, USA

${ }^{51}$ Stockholm Resilience Centre, Stockholm University, 10691 Stockholm, Sweden

${ }^{52}$ Laskeek Bay Conservation Society, 3207 Wharf Way, Queen Charlotte, BC V0T 1S0, Canada

${ }^{53}$ Deakin Centre for Integrative Ecology, School of Life and Environmental Sciences, Deakin University, 221 Burwood Hwy, Burwood, VIC 3125, Australia

${ }^{54}$ Instituto de Biología de Organismos Marinos (IBIOMAR-CONICET), Boulevard Brown 2915, Puerto Madryn (U9120ACD), Chubut, Argentina

${ }^{55}$ Percy FitzPatrick Institute of African Ornithology, DST/NRF Centre of Excellence, University of Cape Town, Rondebosch 7701, South Africa

${ }^{56}$ Arctic Research Centre, Department of Bioscience, Aarhus University, Denmark

${ }^{57}$ National Audubon Society Seabird Restoration Program, 12 Audubon Road, Bremen, ME 04551, USA

${ }^{58}$ Chair Nature Protection and Landscape Ecology, University of Freiburg, Tennebacher Straße 4, D79106 Freiburg, Germany

${ }^{59}$ Instituto de Investigaciones Marinas y Costeras (IIMyC), Universidad Nacional de Mar del PlataCONICET, Deán Funes 3250, Mar del Plata (B7602AYJ), Buenos Aires, Argentina ${ }^{60} 5959$ Shoreline Highway, Bolinas, California 94929, USA

${ }^{61}$ Graduate School of Fisheries Sciences, Hokkaido University, Minato-cho 3-1-1, Hakodate, 0418611, Japan

${ }^{62}$ CEBC, Centre National de la Recherche Scientifique (CNRS), 405 Route de Prissé la Charrière, 79360 Villiers-en-Bois, France

${ }^{63}$ Landcare Research, Tamaki Campus, Auckland, New Zealand 


\section{Abstract}

Reproductive timing in many taxa plays a key role in determining breeding productivity ${ }^{1}$ and is often sensitive to climatic conditions ${ }^{2}$. Current climate change may alter timing of breeding at different rates across trophic levels, potentially resulting in temporal mismatch between the resource requirements of predators, and their prey ${ }^{3}$. This is of particular concern for higher trophic-level organisms, whose longer generation times confer a lower rate of evolutionary rescue than primary producers or consumers ${ }^{4}$. However, the disconnection between studies of ecological change in marine systems makes it difficult to detect general patterns of timing of reproduction ${ }^{5}$. Here, we use a comprehensive meta-analysis of 209 phenological time series from 145 breeding populations to show that on average, seabird populations worldwide have not adjusted their breeding seasons over time (-0.020 days $\left.\mathrm{yr}^{-1}\right)$ or in response to sea surface temperature (SST) $\left(-0.272\right.$ days $\left.{ }^{\circ} \mathrm{C}^{-1}\right)$ between 1952 and 2015. However, marked between-year variation in timing observed in resident species and some Pelecaniformes and Suliformes (cormorants, gannets and boobies), may imply that timing, in some cases, is affected by unmeasured environmental conditions. This limited temperature-mediated plasticity of reproductive timing in seabirds potentially makes these top predators highly vulnerable to future mismatch with lower trophic-level resources ${ }^{2}$. 

and aquatic biota, including species abundance, distributions, behaviours, and interactions ${ }^{6}$. Changes in phenology - the timing of seasonally recurring life-history events - are one of the most apparent responses to rising global temperatures; at higher latitudes many spring and early summer events are advancing over time across a suite of terrestrial, freshwater and marine ecosystems ${ }^{3,2}$. As timing of breeding affects the abiotic conditions and biotic interactions to which parents and their offspring are exposed ${ }^{7}$, breeding phenology is expected to play a key role in mediating the relationship between environmental temperature and fitness ${ }^{1}$.

Globally, many species at higher trophic levels have poor conservation status ${ }^{8}$. Current evidence indicates that the phenology of species occupying higher trophic levels is less responsive to environmental change than that of primary producers and consumers ${ }^{3,2,4}$, making them particularly susceptible to trophic mismatch and the associated negative demographic consequences $^{3,9}$. However, previous studies which have combined estimates of phenological sensitivity (i.e. phenological change over time or in response to temperature) of multiple high trophic-level species to global change $e^{3,2,9-13}$ have typically included few species or focused primarily on mean responses within taxa, trophic levels, or regions. Moreover, most earlier multi-species analyses have ignored sampling error in estimates of phenological sensitivity ${ }^{9,11-}$ ${ }^{14}$ (but see ${ }^{2}$ for an alternative approach) or sources of statistical non-independence, such as phylogeny (but see ${ }^{15}$ ). As such, it is not clear whether the variation in rates of phenological sensitivity reported in the literature is simply the result of the sampling error variance that is characteristic of regression using short time series ${ }^{16,17}$, or represents true variation. If true variation in phenological sensitivity exists, this may arise where the strength of plasticity covaries with attributes of particular species (e.g. body size, feeding ecology, migration strategy), biogeography (e.g. upwelling, latitude, hemisphere or ocean basin), or an interaction between two or more of these effects. Testing the influence of these variables on variation in 
phenological sensitivity at a global scale across multiple populations will help to ascertain general patterns and highlight those taxa and regions most likely to be vulnerable to climate change.

Seabirds are one of the best-studied groups of higher trophic level organisms, and are considered here to include species from the orders Sphenisciformes, Procellariiformes, Suliformes, Pelecaniformes and Charadriiformes. Found throughout the world's oceans, they range in size from $\sim 20 \mathrm{~g}$ to $\sim 30 \mathrm{~kg}$, and generally exhibit long generation times and slow, inflexible life histories. They are more threatened than any other comparable avian group, with the conservation status of many species rapidly deteriorating ${ }^{18}$. Seabirds exhibit considerable interspecific variation in feeding strategies, with breeding season foraging ranges varying from $<10$ to $>1000 \mathrm{~km}$ and foraging depths from $<1 \mathrm{~m}$ to 100 s of metres deep. Outside the breeding season, some species remain close to their colony while others undertake the longest migrations known in the animal kingdom ${ }^{19}$.

Studies of seabird breeding phenology have reported a variety of different trends over time $^{20}$. Among the local environmental drivers of phenology that have been identified, sea surface temperature (SST) is widely reported to correlate with the distribution, abundance and phenology of both local and migratory prey populations ${ }^{21}$, of which the effects on higher trophic level organisms can be compared at global scales. Therefore, changes in temperature driven by climate change could be critical, generating a mismatch with prey availability (see further discussion below $)^{22}$. Directional SST changes and fluctuations have been recorded in the waters surrounding many seabird breeding sites (Figure 1a, b, Supplementary Figure 1), with both metrics of change varying geographically. Large-scale climatic variables, such as the North Atlantic Oscillation and the Southern Oscillation Index may also explain annual variation in reproductive phenology (reviewed in ${ }^{13}$ ). However, using large-scale proxies instead of data on specific climate drivers (e.g. SST) may lead to spurious and simplistic 
assumptions of climate-ecology dynamics ${ }^{23}$. Furthermore, proxies at this scale are not amenable to global analyses, since regional proxies are not equivalent or comparable in a single analysis $^{23}$. Thus, variation in the sensitivity in timing of breeding across species and regions remains unclear (but see ${ }^{17}$ ). Due to their trophic position, global distribution and the numerous long-term studies available, seabirds constitute a tractable and powerful group for a global meta-analysis of breeding phenology. Such an analysis allows us to not only make general inferences about the degree to which breeding phenology has changed both over time and in relation to SST, but also about the life history traits underpinning variation in phenological responsiveness (Table 1). Finally, it allows us to examine predictors of between-year phenological variation, with high variance potentially indicative of phenological sensitivity to one or more unspecified environmental drivers.

We applied a phylogenetic mixed model meta-analysis to a global dataset comprising 209 phenological time series of breeding dates obtained from 145 seabird populations (Figure 1c. Median number of years/time-series $=18 ; \min =5 ; \max =48$. Median sample size/year /time-series $=72 ; \min =6 ; \max =936)$, covering 61 species from five main orders. These taxonomic groups exhibit a wide variety of life-history, migration and foraging strategies, and are distributed from equator to poles across all principal oceanographic regimes. Meta-analyses provide a robust approach for identifying average effect sizes across studies, and for identifying predictors of variation around the average $\mathrm{e}^{24}$. Here, we (i) characterised latitudinal trends in the mean and between-year variance of seabird breeding phenology (laying and hatching dates), (ii) estimated the mean sensitivity of breeding phenology over time and in relation to SST in the waters around the sampled colonies, and (iii) identified predictors (body size, biogeography, phylogeny) of inter- and intra-specific variation around the mean response (mean, variance and both sensitivity measures) of each species/population (for specific predictions see Table $1 \&$ Methods). 

that between-year variance in phenology decreased (Supplementary Table 1, Figure 2a, b), which concurs with earlier results obtained from regional studies ${ }^{25,26}$. The low variance at high latitudes may arise due to the shortened period of favourable conditions and the strong seasonal cue that photoperiod provides, whereas the much greater variance at lower latitudes may relate to the reduction of seasonality and the relatively weaker cue from day length ${ }^{27}$. from $<1$ in the black-browed albatross (Thalassarche melanophris) at New Island, Falklands, consistent with $95 \%$ of annual means occurring within a three-day period, to 1573 in the bluefooted booby (Sula nebouxii) at Isla Isabel, Mexico, consistent with 95\% of annual means occurring within a five-month period. Examination of life history traits potentially explaining this variation (Supplementary meta-data) indicated that resident species were more variable than migrants (Supplementary Table 2, Figure 3b). This result is in accordance with results for terrestrial birds ${ }^{28}$ and may arise if the laying dates of resident species are more sensitive to local foraging conditions as a cue to initiate breeding in anticipation of the timing of future resources. Controlling for biogeographic trends, we find that between-year variance in laying date was highly phylogenetically conserved $\left(H^{2}=0.84,95 \%\right.$ Credible Interval $[\mathrm{CI}]: 0.508-1, n=208$, Supplementary Table 2). From inspection of the best linear unbiased predictors (BLUPs) for the phylogenetic effects, the most threatened $\operatorname{order}^{18}$, Procellariiformes, particularly giant petrels and fulmars (Procellariidae), and albatrosses (Diomedeidae), stood out as least variable in timing of breeding. This response is consistent with a strong reliance on photoperiod as a cue $^{29}$. In contrast, we find that Pelecaniformes and Suliformes (cormorants, gannets and boobies) vary substantially among years in timing of breeding, suggesting that these species may adjust egg laying in relation to some aspect of the local environment (weather, oceanographic conditions or food availability) in the lead-up to the breeding season ${ }^{30}$. 

time (-0.020 days $\mathrm{yr}^{-1}, 95 \% \mathrm{CI}:-0.160-0.129, n=209$, Figure $\left.3 \mathrm{a}\right)$. This is in agreement with 240 previous studies of this species group ${ }^{9,20}$, but the overall slope was much less steep than those 241 from similar analyses of $\mathrm{UK}$ birds ${ }^{3}\left(\right.$ mean $=-0.19$ days $\left.\mathrm{yr}^{-1}\right)$, terrestrial and marine vertebrates ${ }^{3}$ 242 (terrestrial mean $=\sim-0.25$ days $\mathrm{yr}^{-1}$, marine mean $=\sim-0.35$ days $\mathrm{yr}^{-1}$ ) or global estimates of marine species in general ${ }^{9}$ (mean $=\sim-0.4$ days $\mathrm{yr}^{-1}$ ). We found limited evidence for true variation around the mean response (Supplementary Table 3), with $83 \%$ of the variation in raw slope estimates of phenology over time attributable to sampling error arising from linear regressions based on small datasets (Supplementary Table 4). Of the remaining true variation, we found that the mean slope estimates did not differ significantly among oceans (Supplementary Table 3). This result runs counter to previous studies of seabird breeding phenology, which have reported variation in long-term trends among biogeographic realms ${ }^{11,20}$. However, we found some evidence that temporal response may vary among species at shared breeding sites (Supplementary Table 3), although sampling covariance between the different phenological measures is likely to inflate this variance estimate. Among-population variation makes it difficult to predict which species and sites will be most phenologically responsive to changing environments, as it implies that the degree of environmental sensitivity in seabird breeding may be determined by a combination of intrinsic and extrinsic factors ${ }^{31}$. Of the environmental or life history variables we considered, body mass was the only significant positive predictor of the temporal trend (Supplementary Table 3), with larger-bodied species responding at a slower rate over time than smaller species, in accordance with our predictions (Table 1).

Globally we found no evidence that seabirds as a group have shifted their laying date in relation to SST in waters around the breeding site in the three months preceding egg laying (mean $=-0.272$ days ${ }^{\circ} \mathrm{C}^{-1}, 95 \% \mathrm{CI}:-4.896-4.482, n=108$, Figure $3 \mathrm{~b}$, Supplementary Table 
5). The average response is much shallower than the average response of lay date to air temperature reported for $27 \mathrm{UK}$ terrestrial birds (mean $=-3.8$ days ${ }^{\circ} \mathrm{C}^{-1}$ (air temperature) $)^{32}$. In broad agreement with the temporal analysis we found no evidence that true variation in the slope of the covariation with SST is predicted by phylogeny, species, biogeographic region, or life-history traits. We did, however, find significant variation in slopes among sites, and the lowest BLUP was -2.96 days ${ }^{\circ} \mathrm{C}^{-1}(95 \% \mathrm{CI}:-6.00-0.13)$ at Skomer Island, Wales, where SST in the focal time period has increased significantly by $0.6^{\circ} \mathrm{C}$ decade ${ }^{-1}$ since 1982 (Supplementary meta-data 1). In contrast, the most positive BLUP was 7.32 days ${ }^{\circ} \mathrm{C}^{-1}(95 \% \mathrm{CI}$ : $4.96-9.73)$ at Southeast Farallon Island, California, which is located in a highly variable upwelling zone, where inter-annual variance in SST is higher than average (Figure 1b, Supplementary meta-data), a condition that might select for plasticity. So, although on average, seabirds appear to be unresponsive to SST, we cannot rule out the possibility some populations are temperature-sensitive in either direction.

That we could detect no trend in seabird phenology over time or in relation to SST (Supplementary meta-data), suggests that if lower trophic levels are shifting in parallel with changing SST, seabirds, in general, may be at risk from increasing levels of trophic mismatch ${ }^{33}$. To date, there are very few studies that have reported the slope of the phenology of poikilothermic seabird prey and lower trophic levels in relation to SST (but see ${ }^{22}$ ). Differing rates of phenological response between seabirds and their food resources ${ }^{9}$ may leave them short of critical prey during the breeding season under future climate regimes. However, there is limited and mixed evidence on the frequency of climate-induced mismatch ${ }^{17,22}$, and whether it has an impact on breeding success ${ }^{34}$ or population dynamics ${ }^{35}$. Alternatively, any negative fitness consequences of trophic asynchrony may be ameliorated by the ability of some species to alter their behaviour, for example by switching prey or adjusting foraging effort ${ }^{22,36}$. 
Our study represents the most statistically rigorous and spatially representative meta-

288

289

290

291

292

293

294

295

296

297

298

299

300

301

302

303

304

305

306

307

308

309

310

analysis to date of the reproductive phenology of a group of upper trophic-level predators, seabirds. Contrary to previous assertions, we find that once sampling error has been taken into account, in most cases the phenology of seabirds shows no trend over time and appears to be largely insensitive to changing SST. While certain populations may be responding, most of the among-species variation in estimates of phenological sensitivity can be attributed to sampling error. Overall, this inflexibility in breeding phenology in relation to temperature may leave seabirds vulnerable to trophic mismatch arising from shifts in timing of their prey.

Supplementary Information is linked to the online version of the paper at www.nature.com/nature.

Correspondence and requests for materials should be addressed to KK (k.keogan@ed.ac.uk).

\section{Acknowledgements}

The work presented here could not have been carried out without the long-term data collection by field workers at all sites. Many thanks to the staff of the Alaska Maritime National Wildlife Refuge; Department of Fisheries; DPaW; Environment Canada; Natural Resources Canada; New Bedford Harbor Trustee Council; Oamaru Blue Penguin Colony; Phillip Island Nature Parks; Government of Greenland (Ministry of Domestic Affairs, Nature and Environment) in Nuuk; Island Conservation Society for permission to work on Aride Island, Seychelles; Aage V Jensen Charity Foundation; The Norwegian Environment Agency (and its predecessors), the SEAPOP programme (www.seapop.no) and its key institutions: The Norwegian Institute for Nature Research, The Norwegian Polar Institute and Tromsø University Museum; South African National Antarctic Programme; US Fish and Wildlife Service; Government of Tristan da Cunha; the British Antarctic Survey. Specific thanks go to Bill Sydeman, Shae Surman, Mal 
McCrae, Bill Fogg, Murray Davidson, Pia Boschetti, Teresa Catry, Patricia Pedro, Laurent

Demongin, Marcel Eens, Petra Quillfeldt, Brigitte Sabard, Jérôme Moreau, Eric Buchel,

Kerry, Judy Clarke, Akiko Kato, Tomohiro Deguchi, Motohiro Ito, Peter Dann, Leanne

Renwick, Paula Wasiak, Agustina Gómez-Laich, Paula Giudicci, Luciana Gallo, Sabrina

Harris, Dave Houston, Peter Menkhorst, F. I. Norman, Chantelle M. Burke, Noelle Laite, Peter

Mallam, Paul M. Regular, Heather Renner, Nora Rojek, Marc Romano, Leslie Slater, Tim

Birkhead, Jarrod Hadfield, Anthony Gaston and three anonymous reviewers for their helpful

comments.

KK was supported by a Principal's Career Development Scholarship from the University of

Edinburgh. ABP was funded by NERC fellowship (Ne/I020598/1). SL was funded by a NERC

CEH and JNCC. ND and MP were supported with post-doctoral fellowship grants by the

Research Fund - Flanders FWO (1265414N \& 12Q6915N to ND) and (1.2.619.10.N.00 \&

1.5.020.11.N.00 to MP). FQ was funded by the National Research Council of Argentina

(CONICET): PIP 5387/05, PIP 11420100100186 and PIP 11220130100268, Ministerio de

Ciencia, Tecnología e Innovación Productiva Argentina: PICT 04-20343, PICT 13-1229 and

Wildlife Conservation Society research grant (ARG_5AR03). PC and JPG were funded by FCT - Portugal through UID/MAR/04292/2013 granted to MARE and Falkland Islands

Government. WAM and AH supported by NSERC (Discovery Grant [WAM] and PDF [AH]),

Environment Canada, and Memorial University of Newfoundland. AWD is funded by

NSERC, Environment Canada, and the New Brunswick Wildlife Council, by agreement with

Canadian Wildlife Service (Atlantic Region). RAP, MJD and AGW work as part of British

Antarctic Survey Polar Science for Planet Earth Programme (Ecosystems component), funded 
337 Research Fund. The Banter See common tern study was performed under the license of the city of Wilhelmshaven and supported by the Deutsche Forschungsgemeinschaft (BE 916/3 to 9). Data from Béchervaise Island were collected following protocols approved by the Australian Antarctic Animal Ethics Committee and supported through the Australian Antarctic program through Australian Antarctic Science projects 2205, 2722 and 4087. The field work in Norway and Svalbard was an integrated part of the SEAPOP programme, with financial support from the Norwegian Environment Agency, Ministry of Climate and Environment, Ministry of Petroleum and Energy and the Norwegian Oil and Gas Association. The French Polar Institute funded the field work at Hochstetter (IPEV; program "1036 Interactions”), and Ukaleqarteq (program “388”). DGA, GB, KMD, PJK and AL were supported by U.S. National Science Foundation grants OPP 9526865, 9814882, 0125608, 0944411 and 0440643 with logistical support from the U.S. Antarctic Program. POL and PRW were supported by New Zealand's Ministry of Business, Innovation and Employment Grants C09X0510 and C01X1001, with logistical support from N.Z. Antarctic Programme.

\section{Author Contributions}

KK, SL, ABP, SW, FD and RP conceived the study and wrote the manuscript. KK coordinated the study, compiled the dataset and wrote the first draft of the manuscript. KK conducted the statistical analyses under the guidance of ABP and with advice from SL and CAW. All others provided data and comments on later drafts of the manuscript.

Author Information Reprints and permissions information is available at www.nature.com/reprints. The authors declare no competing financial interests.

Competing Financial Interests statement The authors declare no competing financial interests. 
361 1. Visser, M. E. \& Both, C. Shifts in phenology due to global climate change: the need for a yardstick. Procedings R. Soc. B Biol. Sci. 272, 2561-2569 (2005).

363

364

365

366

367

368

369

370

371

372

373

374

2. Thackeray, S. J. et al. Phenological sensitivity to climate across taxa and trophic levels. Nature 535, 241-245 (2016).

3. Thackeray, S. J. et al. Trophic level asynchrony in rates of phenological change for marine, freshwater and terrestrial environments. Glob. Chang. Biol. 16, 3304-3313 (2010).

4. Visser, M. E., Both, C. \& Lambrechts, M. M. Global Climate Change Leads to Mistimed Avian Reproduction. Adv. Ecol. Res. 35, 89-110 (2004).

5. Richardson, A. J. \& Poloczanska, E. S. Under-resourced, under threat. Science. 320, 1294-1295 (2008).

6. Walther, G. et al. Ecological responses to recent climate change. Nature 416, 389-395 (2002).

7. Miller-Rushing, A. J., Høye, T. T., Inouye, D. W. \& Post, E. The effects of phenological mismatches on demography. Philos. Trans. R. Soc. Lond. B. Biol. Sci. 365, 3177-3186 (2010).

8. Purvis, A., Gittleman, J. L., Cowlishaw, G. \& Mace, G. M. Predicting extinction risk in declining species. Proc. R. Soc. London B 267, 1947-1952 (2000).

9. Poloczanska, E. S. et al. Global imprint of climate change on marine life. Nat. Clim. Chang. 3, 919-925 (2013).

10. Chambers, L. E. et al. Phenological changes in the Southern hemisphere. PLoS One 8, 
383

11. Poloczanska, E. S. et al. Responses of marine organisms to climate change across oceans. Front. Mar. Sci. 3, 1-21 (2016).

12. Sydeman, W. J., Poloczanska, E. S., Reed, T. E. \& Thompson, S. A. Climate change and marine vertebrates. Science. 350, 772-777 (2015).

13. Sydeman, W. J., Thompson, S. A. \& Kitaysky, A. Seabirds and climate change: roadmap for the future. Mar. Ecol. Prog. Ser. 454, 107-117 (2012).

14. Parmesan, C. \& Yohe, G. A globally coherent fingerprint of climate change impacts across natural systems. Nature 421, 37-42 (2003).

15. Dunn, P. O. \& Møller, A. P. Changes in breeding phenology and population size of birds. J. Anim. Ecol. 83, 729-739 (2014).

16. Hadfield, J. D. \& Nakagawa, S. General quantitative genetic methods for comparative biology: Phylogenies, taxonomies and multi-trait models for continuous and categorical characters. J. Evol. Biol. 23, 494-508 (2010).

17. Youngflesh, C. et al. Circumpolar analysis of the Adelie penguin reveals the importance of environmental variability in phenological mismatch. Ecology (2017).

18. Croxall, J. P. et al. Seabird conservation status, threats and priority actions: a global assessment. Bird Conserv. Int. 22, 1-34 (2012).

19. Schreiber, E. a \& Burger, J. Biology of Marine Birds. CRC Press (2002).

20. Chambers, L. E., Dann, P., Cannell, B. \& Woehler, E. J. Climate as a driver of phenological change in southern seabirds. Int. J. Biometeorol. 58, 603-612 (2014).

21. Cheung, W. W. L., Watson, R. \& Pauly, D. Signature of ocean warming in global 
405

406

407

408

409

410

411

412

413

414

415

416

417

418

419

420

421

422

423

424

425

22. Ainley, D. . \& Boekelheide, R. . Seabirds of the Farallon Islands: ecology, dynamics and structure of an upwelling-system community. (Stanford University Press, 1990).

23. Mesquita, M. D. S. et al. There is more to climate than the North Atlantic Oscillation: a new perspective from climate dynamics to explain the variability in population growth rates of a long-lived seabird. Front. Ecol. Evol. 3, 1-14 (2015).

24. Nakagawa, S. \& Santos, E. S. A. Methodological issues and advances in biological meta-analysis. Evol. Ecol. 26, 1253-1274 (2012).

25. Wanless, S., Harris, M. P., Lewis, S., Frederiksen, M. \& Murray, S. Later breeding in northern gannets in the eastern Atlantic. Mar. Ecol. Prog. Ser. 370, 263-269 (2008).

26. Burr, Z. M. et al. Later at higher latitudes: large-scale variability in seabird breeding timing and synchronicity. Ecosphere 7, 1-12 (2016).

27. Bradshaw, W. E. \& Holzapfel, C. M. Light, time, and the physiology of biotic response to rapid climate change in animals. Annu. Rev. Physiol. 72, 147-166 (2010).

28. Moussus, J.-P., Clavel, J., Jiguet, F. \& Julliard, R. Which are the phenologically flexible species? A case study with common passerine birds. Oikos 120, 991-998 (2011).

29. Gwinner, E. Circannual clocks in avian reproduction and migration. Ibis 138, 47-63 (1996).

30. Dawson, A. Control of the annual cycle in birds: endocrine constraints and plasticity in response to ecological variability. Philos. Trans. R. Soc. B Biol. Sci. 363, 1621-1633 (2008). 
426 31. Daunt, F. et al. Longitudinal bio-logging reveals interplay between extrinsic and intrinsic carry-over effects in a long-lived vertebrate. Ecology 95, 2077-2083 (2014).

428

32. McLean, N., Lawson, C. R., Leech, D. I. \& van de Pol, M. Predicting when climatedriven phenotypic change affects population dynamics. Ecol. Lett. 595-608 (2016).

33. Durant, J. M., Hjermann, D. O., Ottersen, G. \& Stenseth, N. C. Climate and the match or mismatch between predator requirements and resource availability. Clim. Res. 33, $271-283$ (2007).

34. Burthe, S. et al. Phenological trends and trophic mismatch across multiple levels of a North Sea pelagic food web. Mar. Ecol. Prog. Ser. 454, 119-133 (2012).

35. Reed, T. E., Grotan, V., Jenouvrier, S., Saether, B.-E. \& Visser, M. E. Population growth in a wild bird is buffered against phenological mismatch. Science. 53, 16891699 (2013).

36. Howells, R. J. et al. From days to decades: short- and long-term variation in environmental conditions affect diet composition of a marine top-predator. Mar. Ecol. Prog. Ser. 583, 227-242 (2017). 
Figure 1. SST trends and map of study sites included in the analyses. a) Across year temporal changes in mean Sea Surface Temperature (SST) in the three months prior to breeding across all biogeographic regions represented by slopes between 1982 (when SST time series' began) and 2015 for each site. Each point represents a slope, with positive slopes indicating warming and negative slopes indicating cooling. b) Standard deviation from the mean SST at each site during the same study period. A = Polar, B = Subpolar, $C=$ Temperate, $D=$ Subtropical, $E=$ Tropical. c) The full dataset comprises 209 time series from 61 seabird species and across 64 locations, collected between 1952 and 2015. The data include slopes for 32 genera, 9 families, and 5 orders (Sphenisciformes (6), Procellariiformes (15), Suliformes (3), Pelecaniformes (5), Charadriiformes (32)) and spans all seven continents. The underrepresentation of tropical time series is due to a combination of a paucity of long-term data for these regions and the asynchronous nature of breeding in many tropical species, which diminishes the informativeness of measuring annual phenological central tendency.

\section{Figure 2. Mean and between-year variance in phenology separated by} hemisphere. a) represents the differences in latitudinal gradient between Northern and Southern Hemispheres, where each data point (grey or red) represents the median timing of breeding of a population. Lines (grey = lay date, red = hatch date) represent the delay in phenology approaching the poles in days lat ${ }^{-1}$, and were estimated using values from Supplementary Table 1. b) represents the betweenyear standard deviation in mean timing for residents (represented by red dots) and migrants (grey dots). Lines are plotted from the ecological model and represent the median lay date in the mean year of study of an average surface feeding resident bird, weighing $800 \mathrm{~g}$, in a region where there is no major upwelling system. The nonlinearity in the plot is due to back calculation from the log scale.

Figure 3. Funnel plots of phenological trends in relation to year and sea surface temperature. a) represents year and b) represents sea surface temperature. Each point represents a slope estimate from the meta-analysis, with negative slopes indicating an advance and positive slopes indicating a delay, in phenological trends. Positioning of each point on the $y$-axis indicates the precision (1/S.E) of the estimate. Thus, points with higher precision are expected to converge on the true average response. Lines represent the posterior for the average response or intercept (black) and its $95 \%$ credible intervals (dashed red) from the basic model (Tables S3a, S5a). 

by the model.

\begin{tabular}{|c|c|c|}
\hline \multicolumn{2}{|l|}{ Prediction } & \multirow[t]{2}{*}{ Reason } \\
\hline \multicolumn{2}{|l|}{ Mean Phenology } & \\
\hline Phenology will be later: & at high latitudes & due to stronger photoperiodic cues at high latitudes ${ }^{25,26}$. \\
\hline \multicolumn{3}{|l|}{ Between-year variance } \\
\hline $\begin{array}{l}\text { Higher between-year } \\
\text { variance will be } \\
\text { observed in: }\end{array}$ & $\begin{array}{l}\text { smaller birds } \\
\text { residents \& short-distance } \\
\text { migrants } \\
\text { surface feeders } \\
\text { populations in upwelling } \\
\text { zones }\end{array}$ & $\begin{array}{l}\text { as they are more sensitive to environmental change } \mathrm{e}^{37} \\
\text { because they may be more sensitive to conditions at the } \\
\text { breeding site }{ }^{28} \text {. } \\
\text { which are more constrained in the water column, meaning } \\
\text { that they can only exploit prey near the water surface }{ }^{38} \text {. } \\
\text { due to high variation in productivity in these areas }{ }^{39,40} \text {. }\end{array}$ \\
\hline \multicolumn{3}{|l|}{ Temporal trends } \\
\hline $\begin{array}{l}\text { A steeper negative } \\
\text { slope will be observed: }\end{array}$ & $\begin{array}{l}\text { in birds with smaller body } \\
\text { size } \\
\text { in birds which feed at the } \\
\text { surface } \\
\text { at high latitudes }\end{array}$ & $\begin{array}{l}\text { to avoid incurring fitness costs of thermoregulation when } \\
\text { breeding at higher temperatures }{ }^{37} \text {. } \\
\text { as they may be more sensitive to the timing at which lower } \\
\text { trophic level prey are available }{ }^{38} \text {. } \\
\text { because polar systems are experiencing warming faster } \\
\text { than other areas }{ }^{41} \text {. }\end{array}$ \\
\hline \multicolumn{3}{|c|}{ Sea Surface Temperature trends } \\
\hline \multirow{3}{*}{$\begin{array}{l}\text { A steeper negative } \\
\text { slope will be observed: }\end{array}$} & $\begin{array}{l}\text { in birds with smaller body } \\
\text { size } \\
\text { in residents \& short- } \\
\text { distance migrants }\end{array}$ & $\begin{array}{l}\text { to avoid incurring fitness costs of thermoregulation when } \\
\text { breeding at higher temperatures }{ }^{37} \text {. } \\
\text { as they are likely to respond to conditions at the breeding } \\
\text { site more readily than species which overwinter in different } \\
\text { basins }{ }^{28} \text {. }\end{array}$ \\
\hline & $\begin{array}{l}\text { in birds which feed at the } \\
\text { surface }\end{array}$ & $\begin{array}{l}\text { as they are predicted to be more sensitive to the timing at } \\
\text { which lower trophic level prey are available }{ }^{38} \text {. }\end{array}$ \\
\hline & at high latitudes & $\begin{array}{l}\text { as polar systems are experiencing warming faster than } \\
\text { other areas }{ }^{41} \text {. }\end{array}$ \\
\hline
\end{tabular}


Data collection To prevent an effect of publication bias and to ensure that positive, negative and neutral phenological trends were included, we used only raw time series (see PRISMA checklist). For each time series we used consistent methods to calculate slopes (i.e. rate of phenological change), between-year variance and crucially, standard error. Raw phenological data were compiled from a variety of sources between October 2015 and October 2016. We contacted $120+$ known seabird researchers and owners of time series to request annual data on seabird breeding phenology and life history. Furthermore, requests were made via Twitter and at the World Seabird Conference in Cape Town (October 2015); the Pacific Seabird Group Annual Meeting in Oahu (February 2016); The Seabird Group conference in Edinburgh (September 2016); and the International Albatross and Petrel Conference in Barcelona (September 2016).

Data Annual data on breeding phenology during the period 1952 and 2015 were the median or mean date of laying or the median, mean or first date of hatching of the study population, in units of ordinal days. Population was defined as an individual species at a breeding site. We only considered populations that breed seasonally during spring and summer (austral and boreal) months, as measures of phenological central tendency are not informative for species which breed asynchronously or subannually (i.e. many tropical species ${ }^{19}$ ). Time series' were required to be a minimum of five years for the temporal analysis and ten years for the analysis of SST, although the years did not need to be consecutive. Details of criteria used to choose suitability of time series' are given in Supplementary Table 9, and the field methods used to collect each time series are outlined in the Supplementary Methods. 
511 Colorado, USA, a resource which provides interpolated in situ and satellite SST data on a one512 degree grid $^{42}$.

For each time series we characterised the biogeography at the colony it was located.

514 We collated information on the location (latitude and longitude) and hemisphere of each population, and for our primary fixed effects model we assigned each location to one of the three main oceans: Atlantic, Pacific or Indian. Global climate zones (Equatorial, Tropical, Subtropical, Temperate, Subpolar or Polar) were identified using the classification from Trujillo \& Thurman (2014). These zones correspond to latitudinal bands of similar sea surface temperature and are categorized by levels of precipitation, wind and water temperature ${ }^{43}$. We combined hemisphere, ocean and global climate zone to identify 15 Biogeographic Regions Boundary (upwelling) zone ${ }^{44}$. These are areas of high productivity within the marine environment, and are also highly variable across seasons, years and decades ${ }^{40,45}$.

We collated data on several aspects of the ecology and life history of each species that may affect the phenological slope (with year or temperature), mean or between-year variance. These data were provided by authors and supplemented using online resources: www.audubon.org, www.birdlife.org, nzbirdsonline.org.nz, www.bird-research.jp and www.npolar.no (Supplementary meta-data). Feeding strategy was categorised either as surface feeder (feeding $<1$ metre below the surface), diver (feeding $>1$ metre below the surface), or kleptoparasite/predator (part-time marine foragers). Species which seek out prey by diving under water may be able to exploit a wider range of prey than those constrained to feeding on 533 the surface ( $<1$ metre depth), thus reducing the necessity to adjust breeding phenology to buffer 534 mismatch $^{46-48}$. We also compiled data on average body mass of every species (Supplementary meta-data), as small-bodied seabird species are predicted to be more sensitive to temperature 
change due to the higher cost of thermoregulation ${ }^{37,49}$. Furthermore, body mass can be used as a proxy for trophic level, which is difficult to classify explicitly in seabirds ${ }^{50}$. We used log body mass in analyses. The migration strategy of individuals from each population was assigned based on the behaviour of the majority $(>80 \%)$ of individuals. Long distance transequatorial migrants, and species which spend the winter outside the sector in which they breed were categorised together as "migrants", and those which remain in the same ocean sector throughout the year were classified as "residents". Sectors were defined as North Atlantic, Mediterranean, South Atlantic, Southern Ocean-Atlantic sector, North Pacific, South Pacific, Southern Ocean-Pacific sector, Indian, Southern Ocean-Indian sector.

We took into account phylogenetic relationships among species using 100 samples of the pseudo-posterior species tree ${ }^{51}$ using the Hackett et al. (2008) backbone ${ }^{52}$.

Statistics We used the MCMCglmm package $^{53}$ in R (v 3.2.2; R Core Team 2015), to fit Bayesian generalised linear mixed-effects models (GLMMs). We adopted a random effects meta-analytic (REMA) approach, estimating both fixed and random effects, while taking sampling error characteristic or regression using short time series into account ${ }^{16,24}$.

We included cross-classified random effects to account for and estimate sources of variance, though not every random variable was included in each model (see Tables S1-S5). The model was of the form

$$
y_{i}=\mu+\beta x_{i}+\alpha_{f[i]}+s_{f[i]}+b_{g[i]}+l_{h[i]}+p_{j[i]}+e_{i}+m_{i} \quad \text { eq. } 1 .
$$

where $y$ is the phenological response variable of each time series $i, \mu$ represents the global mean response (intercept), and $\beta x_{i}$ the fixed effects. For each response variable we also included a null model with the intercept as the sole fixed effect, as this allowed us to infer which random terms captured most of the variance. 
560 history ${ }^{16}$ for the $f$ th species. $s_{f[i]}$ is the non-phylogenetic species-specific effect for the $f$ th

561

562

563

564

565

566

567

568

569

570

571

572

573

574

575

576

577

578

579

580

581

582

species. Spatial variation was accounted for via two terms, $g$ th biogeographic region $\left(b_{g[i]}\right)$

(see Supplementary meta-data) and $h$ th site $\left(l_{h[i]}\right)$. In certain analyses we included multiple measures/traits for a time series and in these cases we could fit the interaction between site and species (population) $\left(p_{j[i]}\right)$, which provided us with an estimate of intraspecific geographic variation that is unique to each $\left(j\right.$ th) population. In these cases the residual term $\left(e_{i}\right)$ captures variation within a site and species (population), and we allowed this variance to be heterogeneous across different phenophases (i.e. median lay date, mean lay date, first hatch date, median hatch date, mean hatch date). In other analyses only a single measure/trait was included and in such instances $p_{j[i]}$ was not estimable. In this case the residual term captured variance both due to intraspecific geographic variation that is unique to each species and differences among phenological measures/traits. Our response variables were themselves estimates that have error associated with them and we incorporated sampling error variances as $m_{i}$, which means that the analyses were weighted. For the sampling error term, the amongobservation variance was set to 1 , and for all other random terms the variance was estimated. The specification of these models assumed that random effects for different measures were perfectly correlated. To test whether this impacted on our estimation of phylogenetic signal we then relaxed this assumption and estimated the covariance between random effects for measures of laying and hatching phenology (Variance Structure of Models section, below).

We calculated phylogenetic signal ${ }^{16,54}$ in our response variables $\left(H^{2}\right)$, i.e. the tendency of closely related species to resemble each other more than distantly related species, from $\sigma_{a}^{2}$ (the phylogenetic variance), and $\sigma_{s}^{2}$ (the species variance)

$$
H^{2}=\frac{\sigma_{a}^{2}}{\left(\sigma_{a}^{2}+\sigma_{s}^{2}\right)} \quad \text { eq. } 2 \text {. }
$$


584 We considered the following four response variables and clearly identify where analyses are 585 post hoc rather than a priori:

586 (1) Multi-year mean phenology: we estimated the mean phenology (e.g. average laying date 587 overall) across all years for each time series. Measurement variance in the mean was quantified

588

590

591

592

593

594

595

596

597

598

600

601

602

603

604

605 as the squared standard error. To examine latitudinal trends in mean date we included both absolute latitude and its quadratic term (to test both linear and non-linear effects); hemisphere; and the interaction between latitude and hemisphere as fixed effects. Additional fixed effects were trait (laying and hatching date) and phenological measurement (mean, median, first date). See Table 1 for predictions.

Post hoc tests: mean phenology is delayed as latitude increases in both hemispheres, with a significant quadratic term, such that the slope appears to reach an asymptote toward the poles (Figure 2, Supplementary Table 1). However, seabirds at low latitudes are underrepresented in this study. When we removed three low latitude data points, there was no support for the quadratic relationship (Supplementary Table 1) but the positive linear relationship between

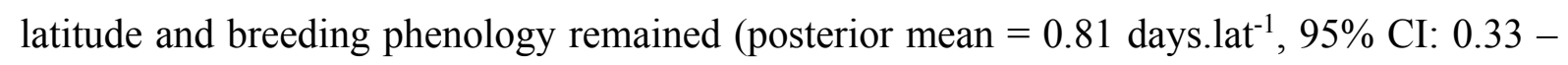
$1.29, n=206$, Supplementary Table 1 ). The intercepts of each measure of phenology (i.e. mean laying date, first hatching date) differed significantly, although a test including the interaction between latitude and phenological measure revealed no difference in their latitudinal slopes (Supplementary Table 1).

(2) Between-year variance in phenology: the response variable (eq. 3) was based on the natural $\log$ of the between-year standard deviation $(s)$ of each population $(\ln \sigma)$, taking into account 
606

607

608

609

610

611

612

613

614

615

616

617

618

619

620

621

622

623

624

625

626

627

the number of years $(n)$. The sampling variance of this measure was quantified as $\left(s^{2} \ln \sigma\right)$ as in eq. $4^{55}$ :

$$
\begin{array}{ll}
\ln \hat{\sigma}=\ln s+\frac{1}{2(\mathrm{n}-1)} & \text { eq. } 3 . \\
\mathrm{s}_{\ln \widehat{\sigma}}^{2}=\frac{1}{2(\mathrm{n}-1)} & \text { eq. } 4 .
\end{array}
$$

(1)

1 The model included phenological trait and measure, latitude and its quadratic term, hemisphere, presence or absence of upwelling and, to test for decadal patterns, the mean year of each time series as fixed effects. We included body mass, foraging and migration strategies in the same model to investigate the effects of life history traits on between-year variance. See Table 1 for predictions.

(1)

7 (3) Temporal trend in phenology: we estimated the linear slope (and standard error) of phenological change over time for each measure (median, mean, first date) and trait (laying or hatching date) of a population using Generalised Least Squares (GLS) in nlme ${ }^{56}$, fitting an autoregressive model of order $1, \mathrm{AR}(1)^{57}$, to take into account temporal autocorrelation in each individual time series. We used these slope estimates in a meta-analysis, and included the squared standard error of the slope to weight the analysis. We included three types of fixed effects: methodology (trait, measure, mean year of time series), life history and ecology (body mass and foraging strategies), and biogeography (ocean basin, hemisphere, latitude). See Table 1 for predictions. We did not make predictions about which ocean basins or hemisphere might show the steepest slopes, but allowed the response to differ among ocean basis and hemispheres in our model. 
628 Post hoc test: our primary ecological fixed effects model categorised locations into one of the 629 three main ocean basins (Atlantic, Indian, Pacific), and included the interaction between

630 latitude and hemisphere as an additional parameter. This approach considered the life histories 631 of wide-ranging polar species which may have large foraging ranges. Yet many species forage 632 near to the colony, or may have evolved alongside the unique oceanographic features of polar systems $^{58}$. To consider these species we re-categorised ocean basins into five discrete water bodies (Arctic, Atlantic, Indian, Pacific, Southern) and ran our ecological model again, replacing the three ocean variable with five oceans, and removing the interaction between latitude and hemisphere.

(4) Phenological response to SST: for each time series we averaged monthly temperature data from the local grid cell for the pre-breeding period (three, two and one month prior to laying, including the month in which laying began) each year. In some cases sea ice cover meant that an average temperature was not estimable and affected time series' were excluded from this analysis. We restricted this analysis to laying dates only, representing each population with a single time series in declining order of preference of measurements: median, mean and first date. In populations for which we only had data on timing of hatching, we back-calculated lay dates using information on the duration of incubation period and average number of eggs.

646 These data were provided by authors and supplemented using online resources: 647 www.audubon.org, www.birdlife.org, nzbirdsonline.org.nz, www.bird-research.jp and www.npolar.no (Supplementary meta-data). Where incubation period was reported as a range, we calculated the central value; this method was used for 70 time series (Supplementary metadata). 
For each colony we calculated the reaction norms and associated standard errors of 652 phenological response to SST (days ${ }^{\circ} \mathrm{C}^{-1}$ ) using the GLS methods as described for the temporal

653

654

655

656

657

658

659

660

661

662

663

664

665

666

667

668

669

670

671

672

673

trends, but retaining year as an additional predictor, in order to de-trend the data and allow us to consider the effects of SST independently of time (Supplementary meta-data). We compared among pre-breeding on the basis of AIC and found very little difference, as expected given the overlap between time periods and month-to-month temporal autocorrelation is SST. Across time series the three-month period had the lowest mean AIC (2 month mean $\triangle \mathrm{AIC}=0.02,1$ month mean $\triangle \mathrm{AIC}=0.50)$ and for consistency we used this time period in subsequent analyses.

We then passed the slopes of phenology regressed on three-month SST into a metaanalysis, with the squared standard error of the slope included for weighting. We tested similar predictions as in (3) above, predicting that timing of laying would be more sensitive to prebreeding SST in species with smaller body mass, which feed on the surface, or that remain in the same ocean basin over winter. Measure, trait and mean year of study were also included as fixed effects.

All models were run for 30,000 iterations on each phylogenetic tree sample, discarding the first 10,000 as burn-in and sampling every $10^{\text {th }}$ iteration. We repeated this process over 100 phylogenetic trees and the pooled posterior distributions take into account both model and phylogenetic uncertainties ${ }^{59}$. Parameter-expanded priors were used for all random effects except the residual, which followed an inverse Wishart distribution. Plots of the mean and variance of the posterior distribution were examined to assess autocorrelation in the posterior samples. Statistical significance of fixed effects was inferred where $95 \%$ credible intervals did not span zero.

\section{Variance Structure of Models:}


674 Our dataset contains five phenophases: median lay date (1), mean lay date (2), first hatch date 675 (3), median hatch date (4) and mean hatch date (5). The core models (with the exception of 676 temperature) run under the assumption that within the residual term $\left(e_{i}\right)$ the variance would 677 be heterogeneous, with each phenophase varying independently of the other four (eq. S1).

678 We used the idh() variance structure function in the MCMCglmm package ${ }^{53}$. This is 679 consistent with phenophases being uncorrelated at the residual level (i.e. covariance $=0$ ) but 680 at the other random effects the correlation between phenophases is assumed to be 1.

$$
\boldsymbol{V}_{e_{i}}=\left[\begin{array}{ccccc}
V_{1,1} & 0 & 0 & 0 & 0 \\
0 & V_{2,2} & 0 & 0 & 0 \\
0 & 0 & V_{3,3} & 0 & 0 \\
0 & 0 & 0 & V_{4,4} & 0 \\
0 & 0 & 0 & 0 & V_{5,5}
\end{array}\right] \text { eq. } \mathrm{S} 1
$$

684 These assumptions can be relaxed for each random effect and the covariance between 685 phenophase can be estimated. We used the us() variance structure function (eq. S2), where $V$ $686=$ variance, $C=$ covariance and $e_{i}=$ random effect.

$$
\boldsymbol{V}_{e_{i}}=\left[\begin{array}{lllll}
V_{1,1} & C_{1,2} & C_{1,3} & C_{1,4} & C_{1,5} \\
C_{1,2} & V_{2,2} & C_{2,3} & C_{2,4} & C_{2,5} \\
C_{1,3} & C_{2,3} & V_{3,3} & C_{3,4} & C_{3,5} \\
C_{1,4} & C_{2,4} & C_{3,4} & V_{4,4} & C_{4,5} \\
C_{1,5} & C_{2,5} & C_{3,5} & C_{4,5} & V_{5,5}
\end{array}\right] \quad \text { eq. S2 }
$$

690 Allowing slopes of phenophases to covary for every random effect may result in a more informative estimate of phylogenetic signal (i.e. perhaps signal is observed at one stage of 
692

693

694

695

696

697

698

699

700

701

702

703

704

705

706

707

708

709

710

711

712

713

6

reproduction but not another), but requires a large amount of data at each level to confidently estimate multiple (co)variances. As our dataset was not large enough to run models with fully unstructured (co)variance, we only estimate the covariance between lay and hatch dates. We restructured the covariance matrix for each random effect (eq. S2) into a 2 x 2 grid (eq. S3).

97

$$
\boldsymbol{V}_{\boldsymbol{R} . \boldsymbol{E}}=\left[\begin{array}{cc}
V_{\text {lay,lay }} & C_{\text {lay, hatch }} \\
C_{\text {lay, hatch }} & V_{\text {hatch, }, \text { atch }}
\end{array}\right] \text { eq. S3 }
$$

8

Thus, three slopes (lay date, hatch date and the covariance between the two) were estimated for each random effect (phylogeny; species; biogeographic region; location and species:location). We ran the three key models (between year variance, temporal and SST) using this error structure to assess whether any of our key insights were sensitive to the assumption that lay and hatch dates are perfectly correlated.

When the assumption of perfect correlation between the two measures was relaxed, we found that phylogenetic signal remained significant for the variance and SST models (Supplementary Tables 6,8 ). We also found some evidence for phylogenetic signal in the temporal model (Supplementary Table 7). These results are in agreement with the key findings of our core models.

Data availability The authors declare that all biological data generated and analysed in this study are available within the article, its supplementary information files and in the following repository: https://github.com/katkeogan/seabird-metaanalysis. The NOAA Optimum Interpolation (OI) Sea Surface Temperature (SST) V2 data that the support the findings of this study are available from NOAA/OAR/ESRL Physical Sciences Division, 
http://www.esrl.noaa.gov/psd/data/gridded/data.noaa.oisst.v2.html. The phylogenetic trees

generated and analysed in this study were obtained from BirdTree, www.birdtree.org.

\section{References}

37. Stevenson, I. R. \& Bryant, D. M. Climate change and constraints on breeding. Nature 406, 366-367 (2000).

38. Furness, R. W. \& Tasker, M. L. Seabird-fishery interactions : quantifying the sensitivity of seabirds to reductions in sandeel abundance, and identification of key areas for sensitive seabirds in the North Sea. Mar. Ecol. Prog. Ser. 202, 253-264 (2000).

39. Reed, T. E. et al. Timing is everything: flexible phenology and shifting selection in a colonial seabird. J. Anim. Ecol. 78, 376-387 (2009).

40. Chavez, F. P. \& Messié, M. A comparison of Eastern Boundary Upwelling Ecosystems. Prog. Oceanogr. 83, 80-96 (2009).

41. Stocker, T.F. et al. IPCC: Summary for Policymakers. Clim. Chang. 2013 Phys. Sci. Basis. Contrib. Work. Gr. I to Fifth Assess. Rep. Intergov. Panel Clim. Chang. 1-29 (2013). doi:10.1017/CBO9781107415324

42. Reynolds, R. W., Rayner, N. A., Smith, T. M., Stokes, D. C. \& Wang, W. An improved in situ and satellite SST analysis for climate. J. Clim. 15, 1609-1625 (2002).

43. Trujillo, A. \& Thurman, H. Essentials of Oceanography (11th Edition). (Pearson Prentice Hall, 2014).

44. Longhurst, A. Ecological Geography of the Sea. (Academic Press, San Diego, 2006).

45. Stenseth, N. C. et al. Studying climate effects on ecology through the use of climate indices: the North Atlantic Oscillation, El Niño Southern Oscillation and beyond. Proc. Biol. Sci. 270, 2087-96 (2003).

46. Passuni, G. et al. Seasonality in marine ecosystems: Peruvian seabirds, anchovy and oceanographic conditions. Ecology 97, 182-193 (2015).

47. Sabarros, P. S., Durant, J. M., Grémillet, D., Crawford, R. J. M. \& Stenseth, N. C. Differential responses of three sympatric seabirds to spatio-temporal variability in shared resources. Mar. Ecol. Prog. Ser. 468, 291-301 (2012).

48. Cabot, D. \& Nisbet, I. Terns. (HarperCollins, London, 2013).

49. Reiss, M. J. The scaling of average daily metabolic rate and energy intake. The Allometry of Growth and Reproduction (Cambridge University Press, 1989).

50. Romero-Romero, S., Molina-Ramírez, A., Höfer, J. \& Acuña, J. L. Body size- based trophic structure of a deep marine ecosystem. Ecology 97, 171-181 (2016).

51. Jetz, W., Thomas, G. H., Joy, J. B., Hartmann, K. \& Mooers, A. O. The global 
diversity of birds in space and time. Nature 491, 444-448 (2012).

751

752

753

754

755

756

757

758

759

760

761

762

763

764

765

766

52. Hackett, S. J. et al. A Phylogenomic Study of Birds Reveals Their Evolutionary History. Science. 320, 1763-1768 (2008).

53. Hadfield, J. D. MCMC methods for multi-response generalized linear mixed models: The MCMCglmm R package. J. Stat. Softw. 33, 1-22 (2010).

54. Housworth, E. A., Martins, E. P. \& Lynch, M. The phylogenetic mixed model. Am. Nat. 163, 84-96 (2004).

55. Nakagawa, S. et al. Meta-analysis of variation: ecological and evolutionary applications and beyond. Methods Ecol. Evol. 6, 143-152 (2015).

56. Pinheiro, J. \& Bates, D. Mixed-Effects Models in S and S-PLUS. (2000).

57. Box, G. E. P. \& Jenkins, G. Time Series Analysis, Forecasting and Control. (1990).

58. Brierley, A. S. \& Kingsford, M. J. Impacts of climate change on marine organisms and ecosystems. Curr. Biol. 19, R602-R614 (2009).

59. Pagel, M. \& Lutzoni, F. Accounting for phylogenetic uncertainty in comparative studies of evolution and adaptation. Biol. Evol. Stat. Phys. 148-162 (2002). 

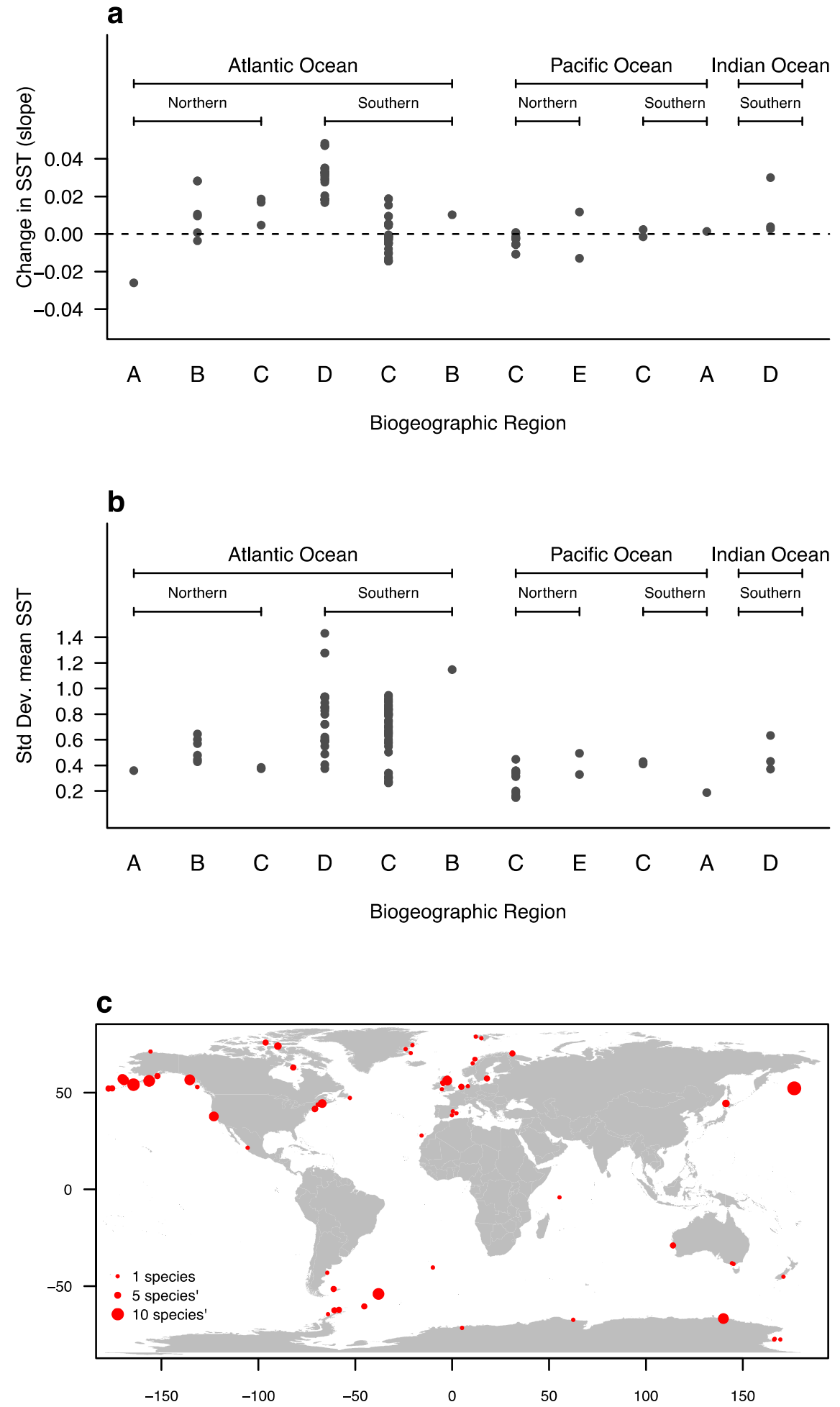
Figure 2
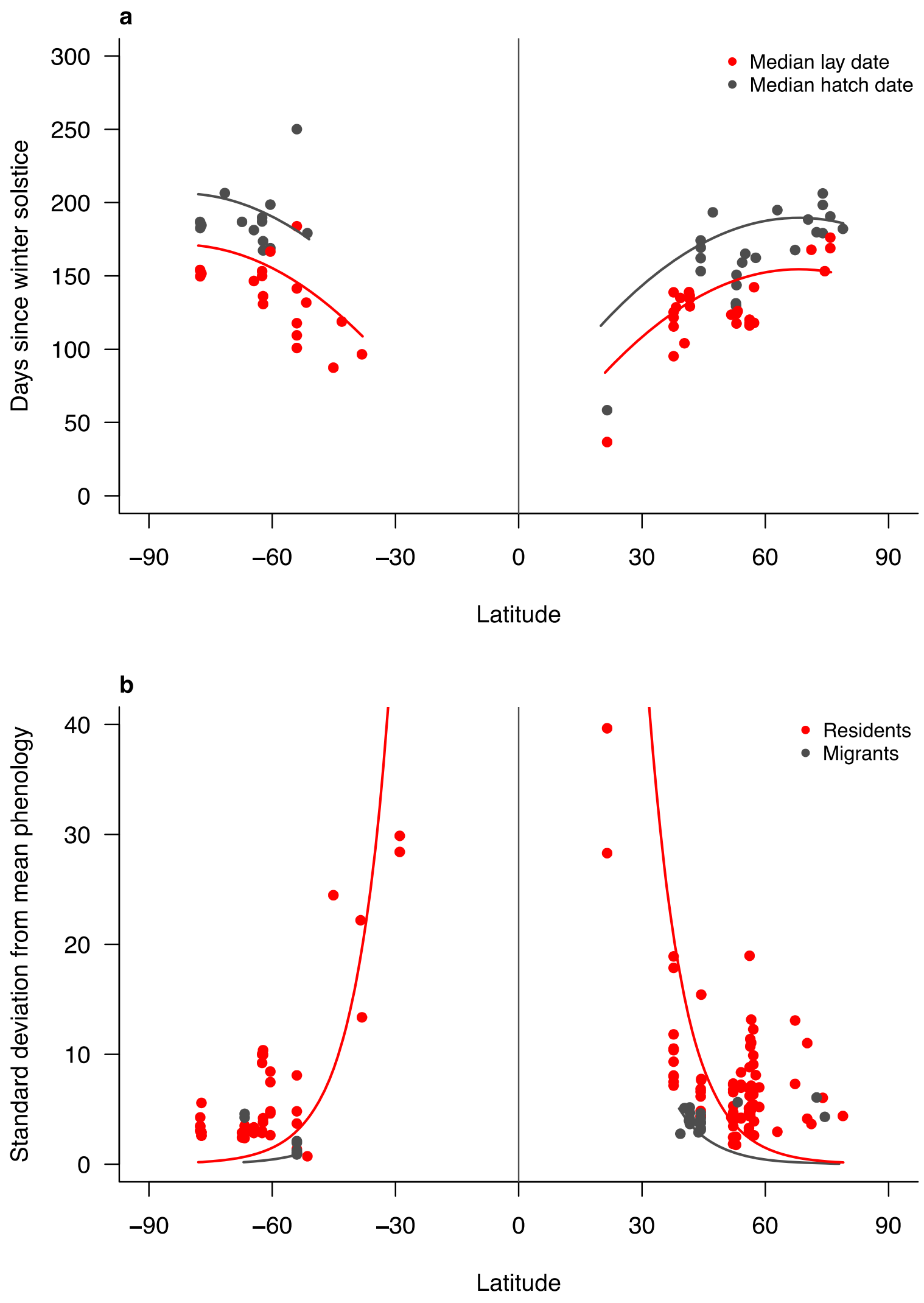
Figure 3

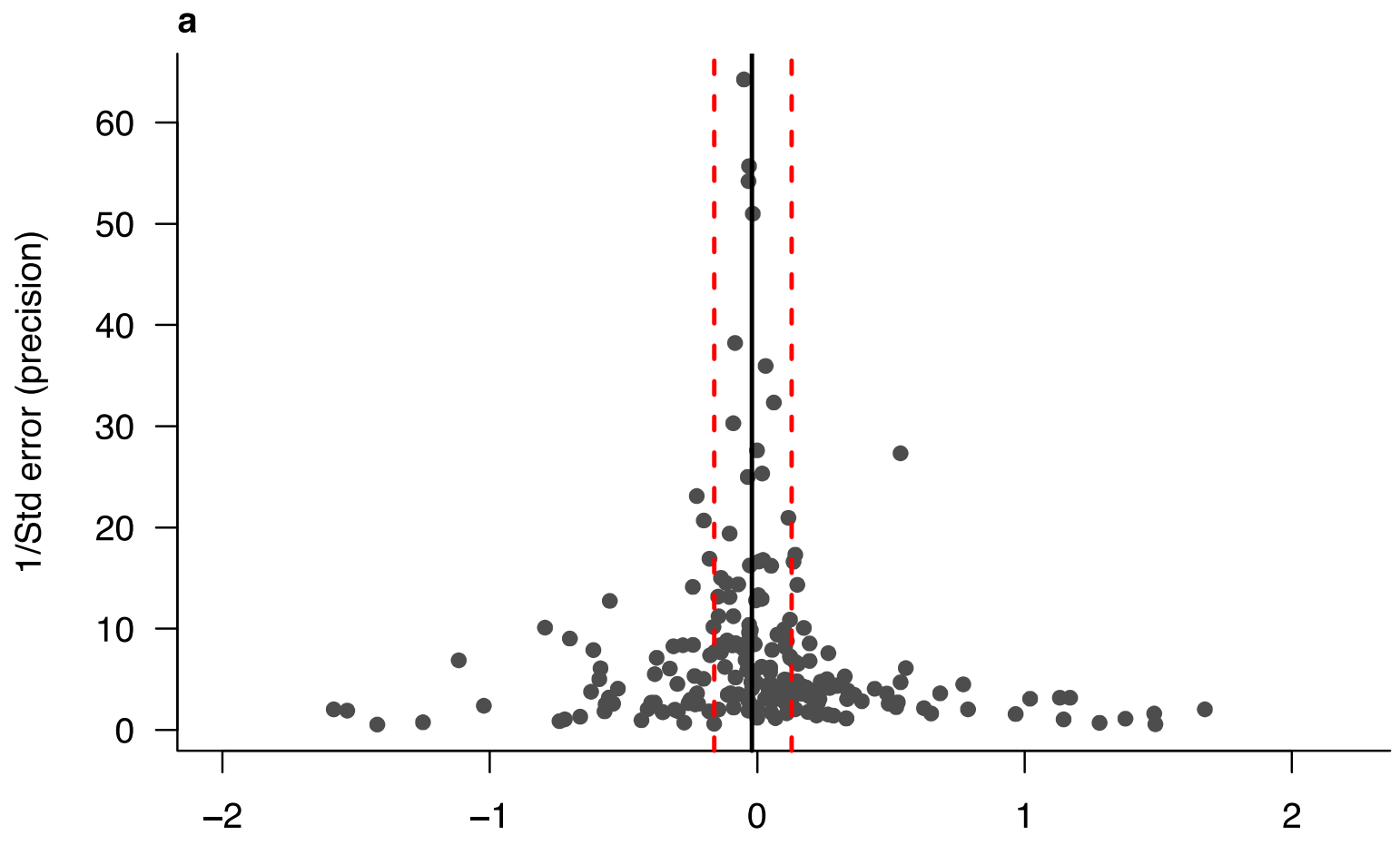

Slope (phenological response days/year)

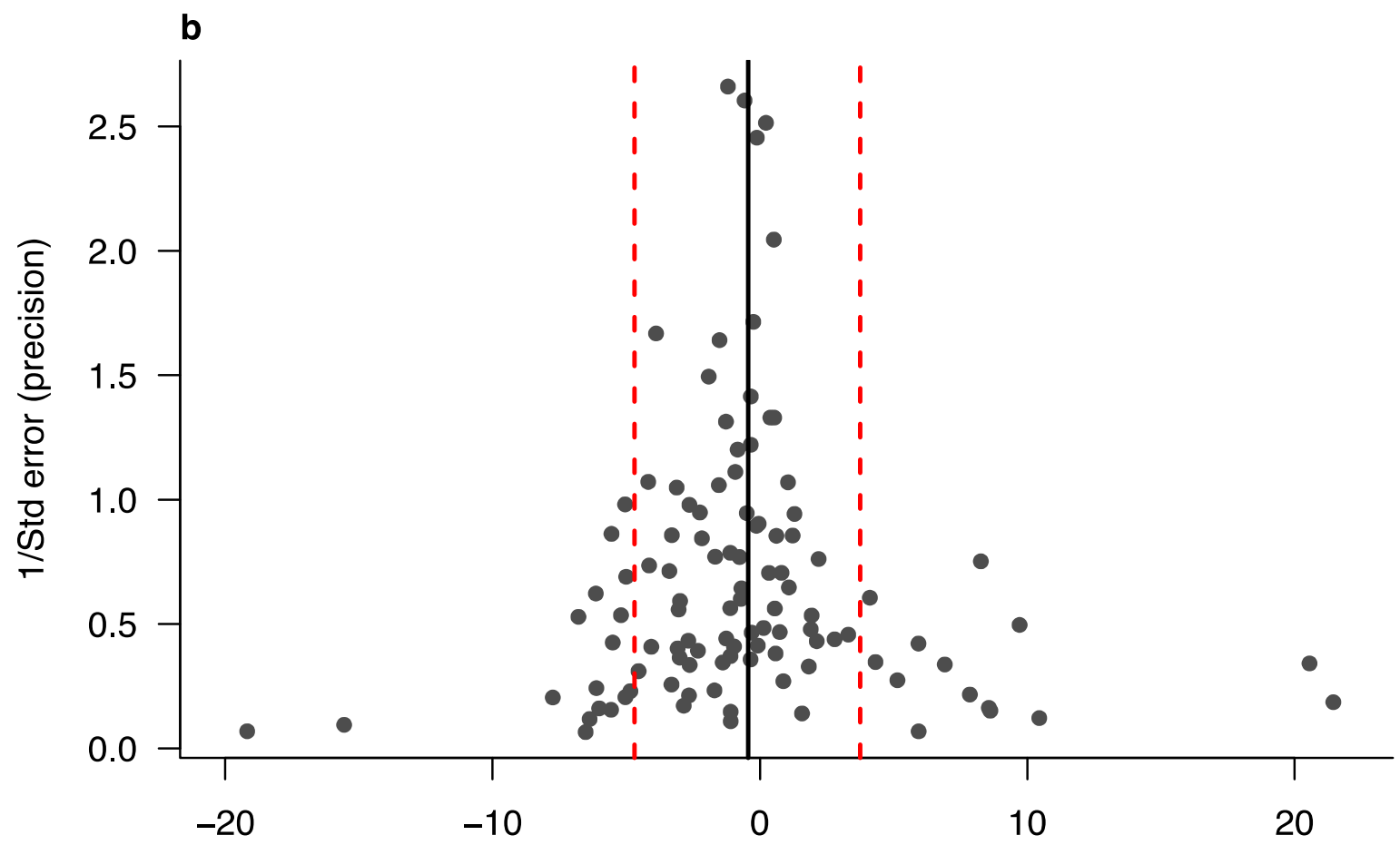


776 Supplementary materials

777

778 